\title{
The Impact of Outcome in Laparoscopic Surgery
}

Debnath BC ${ }^{*}$, Ghosh $\mathrm{A}^{2}$, Chowdhury $\mathrm{AK}^{3}$, Jahangir $\mathrm{R}^{4}$, Alam $\mathrm{F}^{5}$, Joarder PAI ${ }^{6}$, Alam TAHM ${ }^{7}$

\author{
${ }^{1}$ Dr. Bidyut Chandra Debnath, Assistant Professor(r/s), Department of Surgery, Bangabandhu Sheikh Mujib Medical University \\ (BSMMU), Dhaka, Bangladesh \\ ${ }^{2}$ Dr. Abanti Ghosh, Lecterur Physiology, Mugda Medical College, Dhaka, Bangladesh \\ ${ }^{3}$ Dr. Abul Kalam Chowdhury, Associate Professor, Department of surgery, BSMMU, Dhaka, Bangladesh \\ ${ }^{4}$ Dr. Rana Jahangir, Medical Officer, Department of surgery, BSMMU, Dhaka, Bangladesh \\ ${ }^{5}$ Dr. Ferdous Alam, Associate Professor, Department of surgery, BSMMU, Dhaka, Bangladesh \\ ${ }^{6}$ Professor Aminul Islam Joarder, Department of surgery, BSMMU, Dhaka, Bangladesh \\ ${ }^{7}$ Professor AHM Towhidul Alam, Chairman \& Head, Department of surgery, BSMMU, Dhaka, Bangladesh
}

DOI: $\underline{10.36347 / \mathrm{sasj} s .2021 . \mathrm{v} 07 \mathrm{i} 01.005}$

| Received: 17.12.2020 | Accepted: 26.12.2020 | Published: 16.01.2021

*Corresponding author: Dr. Bidyut Chandra Debnath

\section{Abstract}

Introduction: Operating time is interval between the instant of the occurrence of specified input condition to system and the instant of completion of a specified operation. Operations carried out for the correction of deformities and defects, repair of injuries and diagnosis and cure of certain diseases. Controversy exists concerning the importance of operative time on patient outcomes. Objective: The aim of this study was to identify the impact of operative time on outcome in laparoscopic surgery. Methods: Purposive sampling method was applied to get desired number of samples. A total number of 61 cases were enrolled in this study. Data were collected in a pre-designed data collection sheet from the records of laparoscopic surgery cases of Bangabandhu Sheikh Mujib Medical University (BSMMU), Dhaka, Bangladesh after taking permission from the authority. Patients who underwent laparoscopic general surgery procedures (colectomy, cholecystectomy, Nissen fundoplication and inguinal hernia. from the 2017-2019 participant use file were identified. Results: A total of 61 elective general surgical patients who underwent laparoscopic procedures were analyzed. Univariate analyses of deciles of operative time demonstrated a statistically significant trend toward increasing odds of complications with increasing operative time for laparoscopic colectomy $(n=10)$, cholecystectomy $(n=32)$, Nissen fundoplication $(n=4)$, and laparoscopic inguinal hernia repairs $(n=15)$. Multivariate modeling revealed the effect of operative time to remain significant after controlling for additional patient factors. Conclusion: Increasing operative time was associated with increased odds of complications and, therefore, it appears that speed may matter in laparoscopic surgery.

Keywords: Operative time, Laparoscopic surgery, Outcome.

Copyright $(\mathcal{C} 2021$ The Author(s): This is an open-access article distributed under the terms of the Creative Commons Attribution 4.0 International License (CC BY-NC 4.0) which permits unrestricted use, distribution, and reproduction in any medium for non-commercial use provided the original author and source are credited.

\section{INTRODUCTION}

The importance of operative time on patient outcomes in laparoscopic surgery remains controversial [1]. Gallstone disease is one of the most common indications for abdominal surgery in the Western countries. The prevalence of this disease increases with age in all populations and in both sexes and the population is aging in industrialized countries [1, 2]. We know laparoscopic cholecystectomy (LC) is the standard treatment both in case of symptomatic gallbladder stones that in case of acute cholecystitis, but these results consider the general population [3]. Operative time is the result of a complex interaction of patient and provider factors and, at present, there is a paucity of data to examine how the length of a procedure impacts outcome in laparoscopic surgery. It is not known whether longer operative times represent meticulous attention to technique and thereby would reduce complications or whether a longer duration of surgery indicates intraoperative difficulties that would predict increased postoperative complications. Similarly, it is not clear whether shorter operative times represent advanced skills and a smooth intraoperative course or potentially less attention to detail that may place a patient at risk for complications. With increasing importance being placed on operative time to track performance and allocate resources, a better understanding of the relative importance of operative time on the quality of patient care is needed. 


\section{METHODOLOGY AND MATERIALS}

Purposive sampling method was applied to get desired number of samples. A total number of 61 cases were enrolled in this study Data were collected in a predesigned data collection sheet from the records of laparoscopic surgery cases of Bangabandhu Sheikh Mujib Medical University (BSMMU), Dhaka, Bangladesh after taking permission from the authority. Patients who underwent laparoscopic general surgery procedures (colectomy, cholecystectomy, Nissen fundoplication and inguinal hernia from the 2017-2019 participant use file were identified. The effect of operative time on 30-day morbidity was further analyzed for each procedure type using multivariate regression controlling for case complexity and additional patient factors. Patients within the highest deciles were excluded to reduce outlier effect. On the other hand exclusion criteria were defined age of more then 70 , defective mental health and other major or incurable diseases.

\section{RESULTS}

The study population consisted of 61 patients who underwent elective laparoscopic general surgical procedures. These $10 \quad(16.4 \%)$ laparoscopic colectomies, $\quad 32(52.46 \%)$ laparoscopic cholecystectomies, 4(6.55\%) laparoscopic Nissen fundoplications and 15(24.59\%) laparoscopic inguinal hernia repairs. Demographic and patient age distribution are listed in Table 1. This study 10(16.40\%) had colectomy, 32(52.46\%) had cholecystectomy, $4(6.55 \%)$ had nissen fundoplication and 15(24.59\%) had laparoscopic inguinal hernia repairs. Table II demonstrated the Distribution of study patients according to significant of laproscopic. Percentage of patients with cardiovascular, pulmonary, renal comorbidities, and diabetes was highest. The total study population was 61 Patients aged 21 years to above 60 years, in laparoscopic colectomy of operative time was $1.00 \mathrm{OR}$ (Odd ratio) confidence interval (1.003, 1.005) and (10.001) p value, in laparoscopic colectomy of ASA was 1.42 OR(Odd ratio) confidence interval (1.237, $1.632)$ and (10.001) p value, in laparoscopic colectomy of smoking was $1.32 \mathrm{OR}($ Odd ratio) confidence interval $(1.156,1.594)$ and $(10.001) \mathrm{p}$ value, in laparoscopic colectomy of Dyspnea was 1.32 OR(Odd ratio) confidence interval $(1.058,1.655)$ and $(0.014) \mathrm{p}$ value, in laparoscopic colectomy of BMI was 1.01 OR(Odd ratio) confidence interval $(1.001,1.021)$ and $(0.025) \mathrm{p}$ value and in laparoscopic colectomy of hypertension was $1.16 \mathrm{OR}($ Odd ratio) confidence interval (1.014, 1.32 ) and (0.030) $\mathrm{p}$ value. Table II demonstrated the Distribution of study patients according to variable of laproscopic colectomy. The total study population was 61 Patients aged 21 years to above 60 years, in laparoscopic Nissen fundoplication of operative time was $1.01 \mathrm{OR}($ Odd ratio) confidence interval (1.003, $1.011)$ and (10.001) $\mathrm{p}$ value and in laparoscopic Nissen fundoplication of Age was 1.01 OR(Odd ratio) confidence interval $(1.016,1.04)$ and $(10.001) \mathrm{p}$ value. Table IV demonstrated the Distribution of study patients according to variable of laproscopic Nissen fundoplication. The total study population was 61 Patients aged 21 years to above 60 years, in laparoscopic inguinal hernia of operative time was 1.01 OR(Odd ratio) confidence interval $(0.997,1.019)$ and (0.059) $\mathrm{p}$ value, in laparoscopic inguinal hernia of Age was 1.02 OR(Odd ratio) confidence interval (1.007, 1.036) and (0.004) $\mathrm{p}$ value, in laparoscopic inguinal hernia of sex was 0.45 OR(Odd ratio) confidence interval $(0.246,0.822)$ and $(0.009) \mathrm{p}$ value and in laparoscopic inguinal hernia of PVD was $4.56 \mathrm{OR}(\mathrm{Odd}$ ratio) confidence interval $(1.03,20.384)$ and $(0.046) \mathrm{p}$ value. Table $\mathrm{V}$ demonstrated the Distribution of study patients according to variable of laproscopic inguinal hernia.

Table-I: Age distribution of the study population $(\mathbf{n}=61)$

\begin{tabular}{|l|l|l|}
\hline Age Distribution (years) & $\mathbf{n = 6 1}$ & $\mathbf{\%}$ \\
\hline 21 years to 30 years & 22 & 36.06 \\
\hline 31 years to 40 years & 26 & 42.62 \\
\hline 41 years to 50 years & 5 & 8.19 \\
\hline 51 years to 60 years & 5 & 8.19 \\
\hline$>$ 60 years & 3 & 4.94 \\
\hline Total & 61 & 100.00 \\
\hline
\end{tabular}

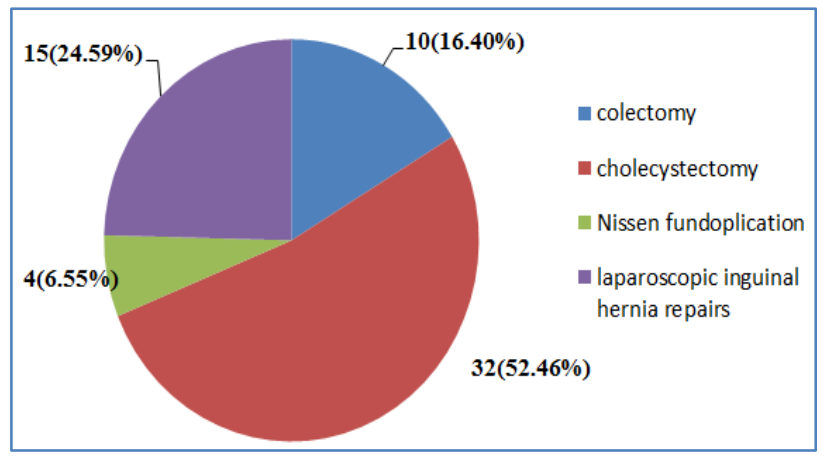

Fig-I: Significant of laparoscopic $(n=61)$

Table-II: Laparoscopic colectomy ${ }^{\mathrm{a}}$

\begin{tabular}{|l|l|l|l|}
\hline Variable & OR & Confidence Interval* & p value \\
\hline Operative time & 1.00 & $(1.003,1.005)$ & $\backslash 0.001$ \\
\hline ASA & 1.42 & $(1.237,1.632)$ & $\backslash 0.001$ \\
\hline Smoking & 1.36 & $(1.156,1.594)$ & 10.001 \\
\hline Dyspnea & 1.32 & $(1.058,1.655)$ & 0.014 \\
\hline BMI & 1.01 & $(1.001,1.021)$ & 0.025 \\
\hline Hypertension & 1.16 & $(1.014,1.32)$ & 0.030 \\
\hline
\end{tabular}


Table-III: Laparoscopic cholecystectomy ${ }^{\mathrm{b}}$

\begin{tabular}{|l|l|l|l|}
\hline Variable & OR & $\begin{array}{l}\text { Confidence } \\
\text { Interval* }\end{array}$ & p value \\
\hline Operative time & 1.01 & $(1.003,1.005)$ & $\backslash 0.001$ \\
\hline Age $(\mathrm{yr})$ & 1.01 & $(1.009,1.018)$ & $\backslash 0.001$ \\
\hline ASA & 1.34 & $(1.130,1.594)$ & 0.001 \\
\hline BMI & 1.02 & $(1.007,1.024)$ & 0.001 \\
\hline CHF & 3.85 & $(1.137,13.036)$ & 0.03 \\
\hline
\end{tabular}

Table-IV: Laparoscopic Nissen fundoplication ${ }^{\mathrm{c}}$

\begin{tabular}{|l|l|l|l|}
\hline Variable & OR & $\begin{array}{l}\text { Confidence } \\
\text { Interval* }\end{array}$ & p value \\
\hline Operative time & 1.01 & $(1.003,1.011)$ & 10.001 \\
\hline Age $(\mathrm{yr})$ & 1.03 & $(1.016,1.04)$ & 10.001 \\
\hline
\end{tabular}

Table-V: Laparoscopic inguinal hernia ${ }^{d}$

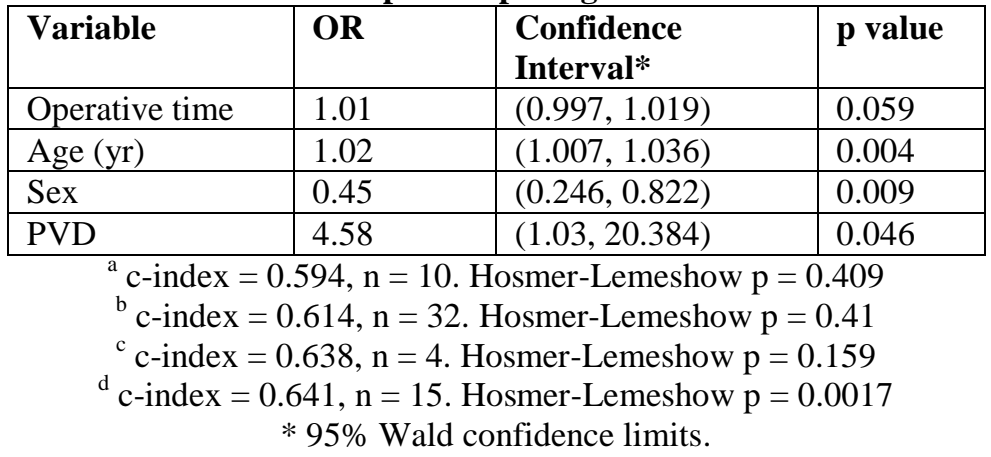

BMI body mass index; ASA American Society of Anesthesiologists Classification (3 vs. 1 or 2); CHF congestive heart failure; PVD peripheral vascular disease

Multivariate regression modeling revealed that increasing operative time remained significantly associated with 30-day morbidity when additional patient factors were controlled for patients who underwent colectomy, cholecystectomy, and Nissen fundoplication but not in patients who underwent laparoscopic inguinal hernia repair. The regression models are presented in Table II, Table III, Table IV and Table V.

For patients undergoing the laparoscopic colectomy patients (Table II), the model included operative time, ASA class, smoking, dyspnea, body mass index (BMI), and hypertension. Within the laparoscopic cholecystectomy model (Table III), operative time and age, ASA, BMI, and CHF were included. Only operative time and age were found to be significantly associated with increased odds of 30-day postoperative complications in the laparoscopic Nissen fundoplication model (Table IV). Operative time was not found to be significant in the laparoscopic inguinal hernia model (Table V). Hosmer-Lemeshow goodnessof-fit testing was not significant for the laparoscopic colectomy, laparoscopic cholecystectomy, and laparoscopic inguinal hernia models but was significant for the laparoscopic Nissen fundoplication model. In addition, the effect of operative time on postoperative wound infection rates was examined within a multivariate model. Increasing operative time was independently associated with increased wound infection rates for laparoscopic colectomy, and laparoscopic cholecystectomy. The impact of level of training of surgical assistant also was explored. The odds of having a trainee as an assistant increased with each decile of operative time, although this trend was significant only within the laparoscopic colectomy group. When operative time was modeled as both a continuous variable and as deciles during sensitivity analysis, the effect of operative time remained significant. Furthermore, the findings did not change when the dependent variable was substituted with any versus no complications as the outcome of interest. When comparable, colectomy, and cholecystectomy patients were analyzed, similar results were found (data not shown).

\section{DISCUSSION}

In this analysis of 61 patients, increasing operative time was independently associated with increased odds of complications in several laparoscopic elective general surgical procedures, colectomy, cholecystectomy, and Nissen fundoplication. This relationship was found to remain statistically significant after risk adjustment to control for additional patient factors. Several authors have examined the relationship of operative time on outcome in general surgery patients with conflicting findings. In a recent study by 
Scheer et al. [6], laparoscopic colon surgery was examined the relationship of operative time on outcome for patients who underwent. The authors found no significant association. This time length corresponds to the highest decile of procedure length in our study, which also was noted to have increased complications. Furthermore, we identified the trend toward increased odds of complications in laparoscopic colectomy patients to be persistent even after excluding the highest decile from our analysis to reduce outlier effect. Using ACS-NSQIP data, Campbell et al. [7], demonstrated that hospitals that were high outliers for surgical site infections had longer surgery times compared with those hospitals that had shorter operative times; this finding is consistent with our results. In our analysis, we also were able to identify a statistically significant positive association between procedure length and wound infection rates for laparoscopic colectomy, and laparoscopic cholecystectomy. Sandblom et al. examined patient outcomes in open hernia repair and identified shorter procedure time (120 min) as being associated with increased risk of reoperation, recurrence, and persistent pain [8]. Although we could not examine these specific endpoints, our findings do contradict their conclusion because we show that shorter operations are associated with lower complication rates. In fact for any procedure type, we could not identify a negative effect of shorter procedure duration on 30-day patient outcome. Other studies have found no relationship between operative time and patient outcome. Liverani et al. [9] performed a review of 250 open "clean" and "clean-contaminated" abdominal surgeries and found no association between length of procedure and number of septic complications, anastomotic dehiscence, or length of stay. Dexter et al. [10], reviewed complication rates in laparoscopic cholecystectomy lasting. The complication rates were found to be $7 \%$ and $3.5 \%$, respectively, although this difference failed to achieve statistical significance. Both studies were retrospective, singleinstitution case series and lacked large sample sizes required to detect differences in procedures with relatively low complication rates. The low complication rate within the laparoscopic hernia group likely contributed to failure of operative time to achieve statistical significance in this group of patients. While we have identified an association, a more complete appreciation of how procedure duration influences patient outcome is needed. This will require an understanding of all factors that may contribute to operative time, including surgical expertise, case complexity, presence of learners, extent of teaching, interaction of surgical teams, and more. This study has several important limitations. An ideal study perhaps would compare the outcomes of faster and slower surgeons rather than compare the outcomes from fast or slow cases. However, surgeon level data were not available. Recognizing that there are likely other factors beyond the individual surgeon that contribute to operative time, additional hierarchical data are needed to further delineate the relationship between procedure time and outcome. Similarly, because hospital effects can have an impact on operative time, multilevel modeling, including hospital level data, also could be important but was not available. Our analysis was limited by the variables available within the SPSS database, and so we could not adjust for all potentially important patient factors and confounders. Our followup was limited to complications occurring within 30 days of the procedure. Our results indicated that the number of complications that a patient experiences increases with increasing operative time for several laparoscopic general surgery procedures. For this reason, operative time does seem to matter in laparoscopic surgery and may be considered a potentially important determinant of patient outcome. To further characterize and quantify the relative importance of operative time in laparoscopic procedures, additional hierarchical multivariate modeling with surgeon level data is required.

\section{CONCLUSION}

Laparoscopic surgery is feasible in all cases in tertiary hospitals where operation facilities and experts are available. Our study concluded that the impact of Laparoscopic surgery is indispensable as Gallbladder diseases surgical methods. This is a Retrospective type of study in a single community with comparatively small number of sample size. So, the study result may not reflect the exact scenarios of the whole country. However, further studies on more samples are needed to have a definitive conclusion.

Funding: No funding sources

Conflict of interest: None declared

\section{REFERENCES}

1. Khuri SF, Henderson WG, Daley J, Jonasson O, Jones RS, Campbell Jr DA, Fink AS, Mentzer Jr RM, Steeger JE, of the Patient PS. The patient safety in surgery study: background, study design, and patient populations. Journal of the American College of Surgeons. 2007 Jun 1;204(6):1089-102.

2. Khuri SF, Henderson WG, Daley J. The patient safety in surgery study: background, study design, and patient populations. J Am Coll Surg. 2007;204(6):1089-1102.

3. Daley J, Forbes MG, Young GJ. Validating riskadjusted surgical outcomes: site visit assessment of process and structure. National VA Surgical Risk Study. J Am Coll Surg. 1997;185(4):341-351.

4. Khuri SF, Henderson WG, Daley J. Successful implementation of the Department of Veterans Affairs' National Surgical Quality Improvement Program in the private sector: the Patient Safety in Surgery study. Ann Surg. 2008;248(2):329-336.

5. Scheer A, Martel G, Moloo H. Laparoscopic colon surgery: does operative time matter?. Dis Colon Rectum. 2009;52(10):1746-1752. 
6. Campbell DA Jr, Henderson WG, Englesbe MJ. Surgical site infection prevention: the importance of operative duration and blood transfusion--results of the first American College of Surgeons-National Surgical Quality Improvement Program Best Practices Initiative. J Am Coll Surg. 2008;207(6):810-820.

7. Sandblom G, Sevonius D, Staël von Holstein C. Impact of operative time and surgeon satisfaction on the long-term outcome of hernia repair. Hernia. 2009;13(6):581-583.
8. Liverani A, Chiarot M, Bezzi M, Angelini L. Il tempo operatorio è realmente un fattore di complicanza? [Is surgery duration really a complication factor?]. Minerva Chir. 1994;49(9):747-750.

9. Dexter SP, Martin IG, Marton J, McMahon MJ. Long operation and the risk of complications from laparoscopic cholecystectomy. $\mathrm{Br} \quad \mathrm{J}$ Surg. 1997;84(4):464-466. 